\title{
Application of New Supercritical Extraction Technology in Extraction and Separation of Effective Components of Traditional Chinese Medicine
}

\author{
Lijuan Cheng \\ Yichun Vocational Technology College, Yichun 336000, China
}

\begin{abstract}
Supercritical CO2 extraction technology uses supercritical CO2 fluid as extractant to extract and separate effective components from plants from liquid or solid. At present, $\mathrm{CO} 2$ is widely used in supercritical fluid, with a critical temperature of $31.265^{\circ} \mathrm{C}$ and a critical pressure of $7.18 \mathrm{MPa}$. The critical conditions are easy to reach. In supercritical state, the density of $\mathrm{CO} 2$ fluid is very sensitive to the changes of temperature and pressure, The widely used separation technologies can be divided into two types: membrane separation and traditional separation. The traditional separation methods can be divided into steam distillation, sublimation, cold soaking, precipitation, percolation, decocting method and Soxhlet extraction, etc. These separation methods have certain limitations. In this paper, SFE technology is combined with modern analytical techniques, such as gas chromatography, high performance liquid chromatography, thin layer chromatography, gas chromatography-mass spectrometry, liquid chromatography-mass spectrometry, etc., so that the component analysis can be carried out more efficiently and quickly. Because of the above advantages, SFE is especially beneficial to the extraction of effective components in traditional Chinese medicine and its preparations.
\end{abstract}

Keywords: New technology of supercritical extraction, Active ingredients of traditional Chinese medicine, Extraction and separation.

\section{Introduction}

Supercritical CO2 extraction technology is a method that uses $\mathrm{CO} 2$ fluid in supercritical state as extractant to extract and separate the effective components in plants from liquid or solid. At present, $\mathrm{CO} 2$ is widely used in supercritical fluid, with its critical temperature of $31.265^{\circ} \mathrm{C}$ and critical pressure of 7. $18 \mathrm{MPa}$, and the critical conditions are easy to reach [1]. In supercritical state, the density of $\mathrm{CO} 2$ fluid is very sensitive to the change of temperature and pressure, and its dissolving capacity is proportional to pressure within a certain range, so the solubility of the extract can be changed by changing the temperature and pressure of the system, so that it can be separated, thus achieving the purpose of separation and extraction [2]. There are many kinds of natural plants in nature, which contain a variety of effective and complex chemical components. These components can be divided into organic acids, volatile oils, coumarins, steroids, glycosides, alkaloids, sugars, plant pigments, etc. the extraction and separation technology of effective components in plants is based on the existing state, shape Solubility and other physical and chemical properties [3]. At present, the new extraction technology has the characteristics of fast extraction speed, high efficiency, good yield and no pollution, and can retain the original effective components to the maximum extent. Choosing the right extraction method can get twice the result with half the effort. The development of biopharmaceuticals and botanicals has become the trend of innovative drugs in the world. All major pharmaceutical countries in the world are systematically screening effective components from natural plants for developing new drugs. However, China, as the birthplace of botanicals, has hindered the development of traditional Chinese medicines due to insufficient analysis of effective components and backward preparation technology [4].

In addition, SFE technology can also be combined with modern analytical technologies, such as gas chromatography, high performance liquid chromatography, thin layer chromatography, gas chromatography-mass spectrometry, liquid chromatography-mass spectrometry, etc., so that component analysis can be carried out more efficiently and quickly [5]. Therefore, it is widely used in the extraction of effective components of traditional Chinese medicine such as volatile oils, flavonoids, alkaloids, saponins, polysaccharides and quinones [6]. At present, the widely used separation technologies can be divided into two types: membrane separation method and 
traditional separation method, and the traditional separation method can be divided into steam distillation method, sublimation method, cold soaking method, precipitation method, percolation method, decocting method method, Soxhlet extraction method, etc. These separation methods have certain limitations [7]. In recent years, the application of new technology in the extraction of traditional Chinese medicine not only conforms to the traditional Chinese medicine theory, but also improves the yield and purity of effective components [8]. This aspect is summarized as follows, in order to provide some reference and guidance for the research and production of modern Chinese medicine pharmacy in China.

\section{New technology of extraction, separation and purification}

\subsection{Supercritical fluid extraction (SFE)}

Supercritical fluid extraction technology is a new separation technology rising in the 1960s. The extractant used in this technology is supercritical fluid (SF). There is a critical point for a specific substance. Above the critical point, the substance is in a non gaseous and non liquid state between gas and liquid. The substances within this range are called supercritical fluid (SF). Under the condition of near normal temperature, when the technology is used to extract and separate the effective components in traditional Chinese medicine, it will hardly destroy the effective components in the product; Third, the technology has good selectivity, and the density of supercritical $\mathrm{CO} 2$ can be changed by controlling pressure and temperature, so as to change its ability to dissolve substances, and extract some components of Chinese herbal medicine [9]. In the corresponding pressure range, the products obtained by extraction are not single. At this time, the best mixed products can be obtained by controlling the conditions, and the supercritical fluid can be changed into gas by heating or depressurizing, so that all the extracted substances can be precipitated and the separated and purified substances can be obtained. The quality of the extracted products is relatively stable. (3) The extraction ability is strong and the extraction rate is high. (4) The low operating temperature of supercritical fluid carbon dioxide extraction $\left(30 \sim 70^{\circ} \mathrm{C}\right)$ can better retain the effective components of traditional Chinese medicine. (5) No organic solvent is used in the extraction process, so the products produced have no harmful solvent residue. In addition, SFE technology can also be combined with modern analytical technologies, such as thin-layer chromatography, gas chromatography, liquid chromatography, gas chromatography-mass spectrometry, liquid chromatography-mass spectrometry, etc., so it can conduct component analysis more efficiently and quickly. Due to the above advantages, SFE is particularly conducive to the extraction of effective components in traditional Chinese medicine and its preparations [10].

\subsection{Ultrasonic extraction technology}

Ultrasonic extraction (UE) is a mature and advanced technology applied to the extraction and separation of functional components such as Chinese herbal medicine in recent years. The strong vibration, high acceleration, cavitation effect, thermal effect and stirring produced by ultrasonic can accelerate the entry of plant effective components into the solvent, so as to improve the extraction rate, shorten the time, save the solvent, and avoid the damage of high temperature to the extracted components. The main driving force of ultrasonic extraction is cavitation effect. There are some vacuum or small bubbles containing a small amount of gas in the liquid, When a large number of ultrasonic waves with a certain frequency act on the liquid, small bubbles with appropriate size can produce resonance phenomenon, and they swell rapidly in the sparse stage of acoustic waves. Ultrasonic-assisted extraction mainly improves the leaching speed of effective components of traditional Chinese medicine by means of ultrasonic cavitation. It can improve the extraction efficiency and shorten the extraction time. The mechanical action of ultrasonic can effectively break the cell wall of plants, so that the effective components can be quickly dissolved in the solvent. Ultrasonic extraction of medicinal materials is not limited by the polarity and molecular weight of components, and is suitable for the extraction of most kinds of Chinese medicinal materials and various components. At present, ultrasonic extraction is widely used in small-scale extraction and analysis of traditional Chinese medicine because of its advantages such as economy, convenience and rapidity. Ultrasonic extraction has high extraction efficiency for alkaloids, glycosides, flavonoids and other compounds in traditional Chinese medicine. Ultrasonic extraction technology is a new method for the extraction of plant functional components, which completely changes the traditional extraction process. It is especially suitable for the extraction of effective components of Chinese herbal medicine. Compared with the conventional decoction method, steam distillation method and solvent extraction method, this method has the following characteristics: low extraction temperature, avoiding the adverse effect of long-time heating on effective components, and high biological activity of the product.

\section{Application of SFE -CO2 technology in extraction of effective components of traditional Chinese medicine}

\subsection{Extraction of effective components of volatile oils from traditional Chinese Medicine}

Volatile oil is the secondary metabolite in plants. The extraction of volatile oil: A thanasios $\mathrm{C} \mathrm{K}$, etc. The volatile oil from garlic was extracted by water distillation, microwave-assisted water distillation and ultrasonic method. It was found that the yield and properties of the volatile oil obtained by the three methods were different, but ultrasonic extraction could reduce the damage to heat- 
sensitive compounds and was easy to operate. The traditional extraction process of volatile oil is steam distillation, which has the disadvantages of long extraction time, high extraction temperature and easy destruction of effective components, resulting in lower extraction yield of volatile oil with lower boiling point. Under the best extraction conditions, the supercritical $\mathrm{CO} 2$ fluid extraction technology was compared with the traditional steam distillation technology. The result was that the volatile oil extracted by supercritical $\mathrm{CO} 2$ was nearly 4 times higher than that by traditional steam distillation. Moreover, the operation time is greatly shortened and the process is simplified. Clinical and modern pharmacological studies show that volatile oil has strong biological activities in many aspects. The traditional extraction process of volatile oil is steam distillation. Due to the defects of long extraction time, high extraction temperature and easy to destroy the effective components, the extraction yield of volatile oil with low boiling point is low. Because the volatile oil has good solubility in supercritical $\mathrm{CO} 2$ fluid and its molecular weight is small, most volatile oils can be directly extracted with supercritical CO2 fluid [14]. The extraction of volatile oil components of traditional Chinese medicine by supercritical $\mathrm{CO} 2$ extraction technology is shown in Table 1.

Table 1 Extraction of volatile oil from traditional Chinese medicine by supercritical $\mathrm{CO} 2$ extraction

\begin{tabular}{|c|c|c|c|c|c|}
\hline $\begin{array}{c}\text { Process } \\
\text { condition }\end{array}$ & $\begin{array}{c}\mathrm{CO} 2 \\
\text { flow/( } \\
1 \mathrm{~h}-1)\end{array}$ & $\begin{array}{c}\text { Extractio } \\
\mathrm{n} \\
\mathrm{pressure} \\
\text { /MPa }\end{array}$ & $\begin{array}{c}\text { Extraction } \\
\text { temperature/ } \\
{ }^{\circ} \mathrm{C}\end{array}$ & $\begin{array}{c}\text { Extractio } \\
\mathrm{n} \text { time } / \mathrm{h}\end{array}$ & $\begin{array}{c}\text { Extractio } \\
\mathrm{n} \text { rate/\% }\end{array}$ \\
\hline $\begin{array}{c}\text { Mint } \\
\text { volatile oil }\end{array}$ & 39 & 14 & 49 & 1.4 & 3.1 \\
\hline $\begin{array}{c}\text { Dried } \\
\text { ginger } \\
\text { volatile oil }\end{array}$ & 31 & 26 & 46 & 4 & 4.6 \\
\hline $\begin{array}{c}\text { Volatile } \\
\text { Oil from } \\
\text { Cyperus } \\
\text { rotundus } \\
\text { and }\end{array}$ & 9 & 36 & 46 & 3 & 7.65 \\
$\begin{array}{c}\text { Ligusticu } \\
\text { m } \\
\text { chuanxion } \\
\text { g Hort }\end{array}$ & 21 & 27 & 50 & 2 & 2.94 \\
\hline $\begin{array}{c}\text { Amomum } \\
\text { cardamom } \\
\text { volatile oil }\end{array}$ & & & & & \\
\hline
\end{tabular}

Extraction of volatile oil from zedoary turmeric $\beta$ Elemene and the volatile oil extracted from Atractylodes macrocephala are extracted by supercritical $\mathrm{CO} 2$ fluid extraction technology under the best conditions or processes. The volatile components of the extract are higher than those of the traditional extract in terms of compound composition and content, which also shows that supercritical $\mathrm{CO} 2$ fluid extraction has the advantages of less time-consuming, high efficiency, complete extraction No organic solvent residue.

\subsection{Extraction of Alkaloids from Traditional Chinese Medicine}

Alkaloids (alkaloid) are a larger class of plant secondary metabolites. At present, there are about $5000 \sim 7000$ kinds of alkaloids isolated from plants. Alkaloids are easy to form salts with various acids in plants, and most of them exist in plants in the form of salts, so their solubility in supercritical CO2 fluid is low. When extracting with SFE$\mathrm{CO} 2$, raw materials generally need to be pretreated with alkaline reagents (such as ammonia, triethylamine, $\mathrm{Ca}$ (OH) 2, Na2CO3 solution, etc.). Extraction of alkaloids: Yuegang $\mathrm{Z}$ et al. In recent years, great progress has been made in the separation of alkaloids from traditional Chinese medicine by supercritical fluid technology, and a large number of valuable alkaloids have been developed. For example, in the extraction of total alkaloids from Leonurus japonicus, the alkalized Leonurus japonicus was extracted by supercritical $\mathrm{CO} 2$ after adding entrainer, which can greatly improve the extraction rate of alkaloids, which is 10 times higher than that of conventional methods [15]. The research on SFE and content determination of Aconitum yadong total alkaloids [16] also showed that the yield and content of Aconitum yadong total alkaloids were lower without alkalization treatment, but after alkalization, the effect was significantly improved. See Table 2 for supercritical CO2 extraction of alkaloids from traditional Chinese medicine.

Table 2 examples of supercritical $\mathrm{CO} 2$ extraction of alkaloids from traditional Chinese Medicine

\begin{tabular}{|c|c|c|c|c|}
\hline $\begin{array}{c}\text { Chinese } \\
\text { herbal } \\
\text { medicine }\end{array}$ & $\begin{array}{l}\text { Main target } \\
\text { components }\end{array}$ & $\begin{array}{l}\text { SFE-CO2 } \\
\text { conditions }\end{array}$ & $\begin{array}{c}\text { Other } \\
\text { extraction } \\
\text { methods }\end{array}$ & References \\
\hline $\begin{array}{l}\text { Datura } \\
\text { flower }\end{array}$ & Scopolamine & $\begin{array}{c}\text { At } 34.9 \\
\mathrm{MPa}, 40^{\circ} \mathrm{C} \text {, } \\
0.1 \mathrm{~m} \mathrm{~L} \\
\text { ammonia } \\
\text { water and } \\
0.2 \mathrm{~m} \mathrm{~L} \\
\text { methanol } \\
\text { as } \\
\text { entrainer } \\
\text { for } 5 \mathrm{~min} \text {, } \\
\text { the } \\
\text { impurities } \\
\text { are less }\end{array}$ & $\begin{array}{l}\text { Alkaline } \\
\text { chloroform } \\
\text { extraction, } \\
\text { solvent } \\
\text { residue }\end{array}$ & [3] \\
\hline Chi chi & Piperine & $\begin{array}{c}38.5 \mathrm{MPa}, \\
70^{\circ} \mathrm{C}, 5 \\
\text { min, yield } \\
2.92 \%\end{array}$ & $\begin{array}{c}\text { Traditional } \\
\text { solvent } \\
\text { method is } \\
\text { time- } \\
\text { consuming } \\
\text { and } \\
\text { complex in } \\
\text { post- } \\
\text { treatment }\end{array}$ & [4] \\
\hline $\begin{array}{c}\text { Light } \\
\text { mushroom } \\
\text { seed }\end{array}$ & Colchicine & $\begin{array}{l}10 \mathrm{MPa} \text {, } \\
45^{\circ} \mathrm{C}, \\
\varphi=76 \% \\
\text { ethanol as } \\
\text { entrainer, } \\
\text { the yield is } \\
1.25 \text { times } \\
\text { that of } \\
\text { solvent } \\
\text { method }\end{array}$ & $\begin{array}{l}\text { The yield of } \\
\text { traditional } \\
\text { solvent } \\
\text { method is } \\
\text { low }\end{array}$ & [5] \\
\hline Cork tree & $\begin{array}{l}\text { Berberine and } \\
\text { palmatine }\end{array}$ & $\begin{array}{l}\text { Methanol } \\
\text { is used as } \\
\text { entrainer }\end{array}$ & $\begin{array}{c}\text { Traditional } \\
\text { solvent } \\
\text { method is } \\
\text { time } \\
\text { consuming }\end{array}$ & [6] \\
\hline $\begin{array}{c}\text { Nux } \\
\text { vomica }\end{array}$ & Dening & $\begin{array}{c}\text { Ammonia } \\
\text { as alkaline } \\
\text { agent and } \\
\text { acetone as } \\
\text { entrainer }\end{array}$ & $\begin{array}{l}\text { Chloroform } \\
\text { extraction } \\
\text { efficiency } \\
\text { is low }\end{array}$ & [7] \\
\hline $\begin{array}{l}\text { Corydalis } \\
\text { tuber }\end{array}$ & Tetrahydropalmatine & $\begin{array}{l}\text { Benzene as } \\
\text { entrainer, } \\
\mathrm{Ca}(\mathrm{OH}) 2 \\
\text { as alkaline } \\
\text { agent, } 20 \\
\mathrm{~m} \text { in }\end{array}$ & $\begin{array}{c}\text { Traditional } \\
\text { solvent } \\
\text { method is } \\
\text { time- } \\
\text { consuming } \\
\text { and } \\
\text { complicated }\end{array}$ & [8] \\
\hline
\end{tabular}


The ultrasonic method was used to extract nicotine from drugs. It was found that the extraction rate of conventional cold immersion method for 24 hours could be obtained in less than 20 minutes, and the amount of solvent was only $1 / 6$ of that of conventional method. There are many kinds of alkaloids, generally referring to the basic nitrogencontaining compounds existing in dicotyledons. Most of them have complex nitrogen-containing heterocyclic structure (nitrogen is mostly contained in the ring). Adding suitable entrainers can also improve the solubility of extracted components, and at the same time, improve the extraction selectivity and increase the purity of extracted components. Commonly used entrainers are mostly methanol, ethanol, acetone, chloroform, etc. Alkaloids have significant physiological effects, such as acting on nervous system, cardiovascular system, antiinflammatory, antibacterial, antiviral, anti-tumor and antimalarial effects, etc.

\section{Conclusions}

With the acceleration of the modernization of traditional Chinese medicine, supercritical fluid extraction technology has broad prospects in the extraction and separation of traditional Chinese medicine. It has the characteristics of fast, high extraction rate and less environmental pollution. However, with the all-round development of science and technology, the traditional extraction methods and the above eight newer extraction and separation technologies will develop together, and even more convenient and fast separation technologies will be born in the process of complementarity and intersection. The use of various analytical methods and instruments has a certain scope of application and their advantages and disadvantages. In the analysis process of effective components of traditional Chinese medicine, we should comprehensively consider the specific analysis according to the specific situation to determine the best extraction, separation, analysis and determination method. In the practice of scientific research and production, it is necessary to analyze specific problems in order to select the best extraction method, which should not be blindly selected. In the future, the extraction technology of effective components from natural plants will be safer, more efficient and more environmentally friendly, and the effective components from natural plants will play a role in more fields. Strengthen the application of new technology, study the influence of new technology on the extraction and separation of different drugs, seek the best operating conditions and mechanism, and design the production equipment and process in a targeted manner, so as to realize the leap-forward development of Chinese traditional medicine industry and make greater contributions to human health.

\section{References}

1. Wang Wuying. Application of new supercritical extraction technology in the extraction and separation of active ingredients of traditional Chinese
medicine[J]. Chinese Medical Guide, 2017, 015(035): 190-191.

2. Liu Na. The application of supercritical fluid extraction technology in the extraction of traditional Chinese medicine[J]. Guangzhou Chemical Industry, 2017, 45(024):31-33.

3. Ding Yuanqing, Wu Xiujuan, Hao Wenyan, et al. Research progress on extraction technology and analysis methods of active ingredients in traditional Chinese medicine $[\mathrm{J}]$. Shandong Chemical Industry, 2017, 46(003): 59-60.

4. Deng Qiaoyu, Jiang Shan, Chen Yudan, Chen Xingguang, Liang Xu, Li Yuzhao, Yuan Jingquan. Application progress of supercritical carbon dioxide extraction technology in the field of traditional Chinese medicine[J]. China Pharmaceuticals, 2020, v.29; No.516(17) :7-11.

5. Deng Peng, Wei Feixue, Wen Wen, et al. Comparative study on extraction of volatile oil from Ligusticum chuanxiong medicinal material by supercritical CO_2 and steam distillation[J]. Journal of Pharmaceutical Practice, 2020, v.38(02):60-63.

6. Chen Yongxing, Chen Yongdong. Analysis of the current situation and technological development of Chinese traditional medicine extraction equipment [J] Journal of Science \& Technology Economics, 2016, 000(004): 75-76.

7. Xie Weiyou[1], Yu Haofei[1], Zhang Lanchun[2], et al. Supercritical $\mathrm{CO} 2$ extraction process of the effective ingredients of Chinese medicine Cui Ling Dan [J]. Journal of Kunming Medical University, 2017, 038(005): P.5-9.

8. Quan Chunmei. Two methods of extracting peony essential oil components and their antioxidant activity [J]. Journal of Gansu University of Traditional Chinese Medicine, 2018, 035(006): P.3236.

9. Wang Haidong, Han Rongxin, Zhang Hongyin, et al. Fractional extraction of Schisandra protein by Osborne method and comparison of antioxidant activity $[\mathrm{J}]$. Food Industry Science and Technology, 2021, 42:1-7.

10. Wei Xiaonan, Hao Tiecheng. Research progress on new technology of Chinese medicine extraction[J]. Chinese Wild Plant Resources, 2020, v.39; No.198(09):51-54. 